\title{
COMPLEMENT AND ITS COMPONENTS IN HUMAN CEREBROSPINAL FLUID ${ }^{1}$
}

\author{
By MICHAEL HEIDELBERGER AND ROBERT H. MULLER
}

\author{
(From the Department of Medicine, College of Physicians and Surgeons, Columbia University, \\ and the Presbyterian Hospital, New York City)
}

(Received for publication August 5, 1948)

It has been stated that normal human cerebrospinal fluid (CSF) does not contain complement $(1,2)$. Complement $\left(C^{\prime}\right)$ has been noted, however, in CSF from occasional cases of meningitis and its presence has even been used as an indication of the permeability of the meningovascular barrier (Weil \& Kafka, in Katzenelbogen [1]). It has also been claimed that the absence of $\mathrm{C}^{\prime}$ activity in normal CSF was due to lack of midpiece (3).

Since these observations were made, more sensitive methods for the estimation of $C^{\prime}$ have become available. These are based upon the spectrophotometric measurement (4) of the 50 per cent hemolytic unit $\left(\mathrm{C}_{\mathbf{H 5 0}}^{\prime}\right)$ in the presence of adequate amounts of $\mathrm{Ca}^{++}$and $\mathrm{Mg}^{++}(5,6)$. Improvements have also been made in the tests for the four recognized components of $C^{\prime}(7)$. The question of the presence or absence of $\mathrm{C}^{\prime}$ in spinal fluid was therefore reexamined with the help of these methods.

Because rather large quantities of CSF were required, samples collected prior to the taking of pneumo-encephalograms were used. ${ }^{2}$ Cases showing infections of the central nervous system were excluded; otherwise, few of the samples could be considered entirely normal CSF. The fluids are listed in the table in order of increasing total protein content, with the hospital discharge diagnoses of the patients. All samples were examined for red blood cells, and when unusual numbers of these were found the fluids were excluded, since any $\mathrm{C}^{\prime}$ found might have been due to adventitious admixture with blood.

About one-third of the fluids showed $\mathrm{C}^{\prime}$ activity when tested directly by addition of 4 or $5 \mathrm{ml}$. to $1.5 \mathrm{ml}$. of a suspension of sensitized sheep red cells and sufficient buffer to give a total volume of $7.5 \mathrm{ml}$. as described by

1 The work reported in this communication was carried out in part under the Harkness Research Fund of the Presbyterian Hospital and in part under a grant from the Rockefeller Foundation.

2 The authors wish to thank Dr. Elvin A. Kabat, Neurological Institute, New York City, and Dr. Hattie E. Alexander, Babies' Hospital, New York City, for the fluids.
Mayer et al. (4-6). Samples showing less than 3 per cent lysis are listed as non-lytic since the optical densities in the spectrophotometer were roughly only double those of the blanks.

At this low level, however, the test for $C^{\prime}$ is extremely insensitive as the von Krogh equation relating the quantity of $C^{\prime}$ to hemolysis $(4,5)$ indicates that 0.5 of a 50 per cent hemolytic unit is required to give 3 per cent hemolysis. An indirect method of estimation of $\mathrm{C}^{\prime}$ activity was therefore considered more appropriate, and the samples were also tested by addition of preferably several different volumes to an accurately estimated portion of diluted human serum $\mathrm{C}^{\prime}$ approximating a 50 per cent hemolytic unit, $1.5 \mathrm{ml}$. of a suspension of sensitized red cells and sufficient buffer as above.

The quantity of human $C^{\prime}$ to be used may be determined as follows: A 1:50,1:75, or $1: 100$ dilution of human serum, depending upon its $\mathrm{C}^{\prime}$ activity, is made up in the saline-veronal buffer containing $0.0005 \mathrm{M} \mathrm{MgCl}_{2}$ and $0.00015 M \mathrm{CaCl}_{2}$ as described by Mayer et al. (5). With the aid of calibrated pipettes, accurately measured $1.5,2.0$, and $2.5 \mathrm{ml}$. portions of the diluted serum are mixed into $50 \mathrm{ml}$. centrifuge tubes containing $1.5 \mathrm{ml}$. $\left(5 \times 10^{8}\right)$ sensitized sheep erythrocytes and the above buffer, to make a final volume of $7.5 \mathrm{ml}$. The tubes are capped and, after incubation in a water bath at $37^{\circ} \mathrm{C}$. for $45 \mathrm{~min}$., with occasional shaking, are centrifuged for $10 \mathrm{~min}$. at 2000 r.p.m. The supernatants are decanted with care and the degree of hemolysis is estimated spectrophotometrically and the $C_{\text {H50 }}^{\prime}$ calculated (4). The optimal amount of human $\mathrm{C}^{\prime}$ to which to add the CSF is in the range 0.8 to $0.9 \mathrm{C}^{\prime}{ }_{\mathrm{H} 50}$, and in this range an increase of $0.03 \mathrm{C}^{\prime}$ Ho should be significant. The human $\mathrm{C}^{\prime}$, if sterile, may best be preserved in small sealed glass ampoules in a $\mathrm{CO}_{2}$ box. Once it has been standardized, a fresh ampoule may be opened for each set of CSF, but blanks, in duplicate, containing the predetermined volume of $C^{\prime}$ dilution and the hemolytic system should always be run along with the tubes containing $C^{\prime}$ and CSF.

In all but two CSF samples tested with a fraction of a $\mathrm{C}^{\prime}$ rso of human $\mathrm{C}^{\prime}$, an increase in hemolysis was noted over that of the $\mathrm{C}^{\prime}$ itself. The results of these experiments are given in Table $I$ as the difference in 50 per cent hemolytic units $\left(\mathrm{C}_{\mathrm{H} \text { (50) }}^{\prime}\right)$ above that of the control human $\mathrm{C}^{\prime}$ dilution alone. These values are not all directly comparable, since only nine samples were tested at different volumes and six with more than one fraction of a $\mathrm{C}_{\text {Hso. }}^{\prime}$ For example, CSF 21 was tested by addition of $1.0,2.0$, and $4.0 \mathrm{ml}$. to $0.8 \mathrm{C}_{\mathrm{B} 50}^{\prime}$ of human $\mathrm{C}^{\prime}$ and 
TABLE I

Complement and its components in spinal fluids from patients with various conditions

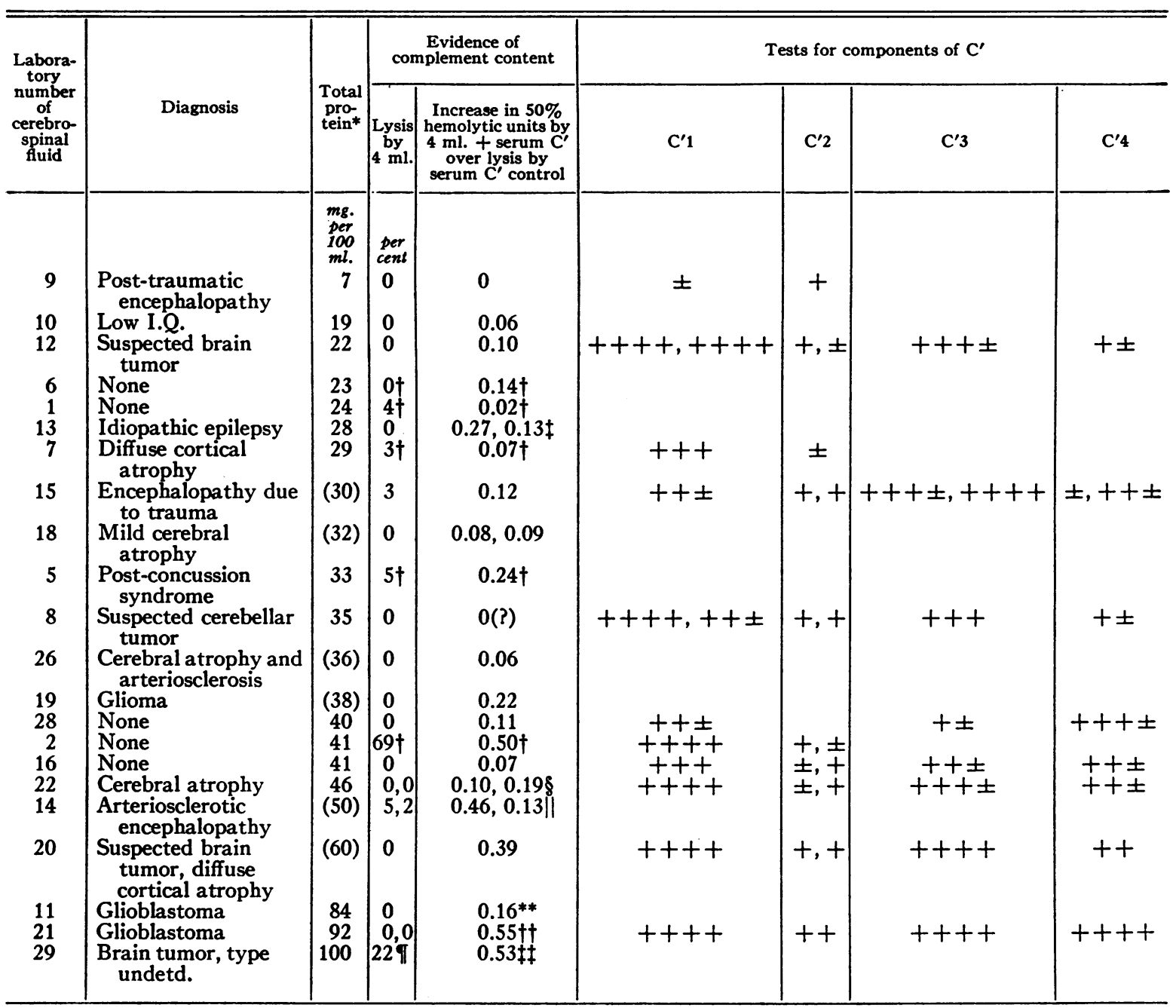

* Analyses by the laboratories of the Neurological Institute and the Babies' Hospital. Values in parentheses were carried out on another sample taken within one week.

$\dagger 5.0 \mathrm{ml}$. CSF used. $1.0 \mathrm{ml}$. of CSF 5 increased the activity of human $\mathrm{C}^{\prime}$ by $0.1 \mathrm{C}^{\prime}{ }_{\mathrm{H} 0} ; 1.0 \mathrm{ml}$. of CSF 6 gave an increase of $0.03 \mathrm{C}^{\prime}{ }_{\mathrm{H} 50} ; 1.0 \mathrm{ml}$. of CSF 7 gave no measurable increase. The value of $0.02 \mathrm{C}^{\prime} \mathrm{H}_{50}$ for CSF 1 is considered significant only in connection with the positive direct test.

‡ The second value was obtained after storage in the $\mathrm{CO}_{2}$ box for 5.5 months in a rubber-capped bottle. The sample absorbed much $\mathrm{CO}_{2}$ and the acidity was neutralized with $0.1 \mathrm{~N}$ and $\mathrm{N} \mathrm{NaOH}$ before the tests were run. Identical values were obtained with 2.5 and with $4.0 \mathrm{ml}$. of the sample, indicating an anticomplementary effect for the larger amount. This occurred whether the additions were made to 0.6 or to $1.2 C^{\prime}{ }_{50}$ of human $C^{\prime}$.

After 4.5 months in the dry ice box.

II After five months in the dry ice box.

I $3.0 \mathrm{ml}$. gave only $10 \%$ hemolysis, but this corresponds to $0.62 \mathrm{C}^{\prime}{ }_{\mathrm{H} 50}$, a value proportional to that for $4.0 \mathrm{ml}$., 0.78 . Hence the sample had no anticomplementary effect in the larger amount.

** Although negative in its original state, a portion, dialyzed under negative pressure in the cold to one-fourth its volume in a period of five days, showed $7 \%$ lysis on the direct test with $4.0 \mathrm{ml}$. and 0.31 increase in $\mathrm{C}^{\prime} \mathrm{H}_{50}$ with $2.0 \mathrm{ml}$. on the indirect test, equivalent to $2 \%$ and $0.16 \mathrm{C}^{\prime}{ }_{50}$ on the original volume, with no allowance for deterioration. The initial indirect test showed $0.03 \mathrm{C}^{\prime} \mathrm{H}$ s.

it With $0.84 \mathrm{C}_{\mathrm{H}_{50}}^{\prime}$ of human $\mathrm{C}^{\prime}, 1.0 \mathrm{ml}$. CSF 21 gave an increase of $0.15 \mathrm{C}^{\prime} \mathrm{H}_{60}, 2.0 \mathrm{ml}$. an increase of 0.30 . In another experiment with $1.27 \mathrm{C}^{\prime} \mathrm{Hs0}, 3.5 \mathrm{ml}$. gave an increase of only 0.20 .

$\ddagger$ Obtained with $3.0 \mathrm{ml}$. An increase of $0.33 \mathrm{C}^{\prime} \mathbf{H}_{50}$ was given by $2.0 \mathrm{ml}$. This sample, also, was not anticomplementary in the quantities used. In this instance, also, there was little difference whether the test was carried out with 0.9 or with $1.3 \mathrm{C}_{\mathrm{H} \text { so. }}^{\prime}$ It appears preferable, however, to add the CSF to somewhat less than $1 \mathrm{C}^{\prime} \mathrm{Hs0}$ of human $\mathrm{C}^{\prime}$, since the lytic curve flattens out greatly above 1.3 units and the uncertainties of analysis are therefore greater. 
showed a greater increase in lysis per milliliter of CSF the smaller the amount of CSF used. A $1.0 \mathrm{ml}$. portion of CSF 5 also showed a relatively greater increase in lysis than the $4.0 \mathrm{ml}$. sample, but this was not true of CSF 6. Similarly, CSF 13 caused a relatively greater increase at the $2.5 \mathrm{ml}$. level than at $4.0 \mathrm{ml}$, but CSF 14,18 , and 22 did not. It is therefore probable that the results given for some of the other CSF samples do not represent maximal values but reflect instead a balance between the activity of $C^{\prime}$ and the anticomplementary properties of the individual CSF.

Qualitative tests of $C^{\prime}$ components were also made in many instances, with reagents for $C^{\prime} 1$ and $C^{\prime} 4$ prepared from guinea pig serum according to Bier et al. (7). Tests for $\mathrm{C}^{\prime} 3$ were made with a reagent obtained by incubation of $1.0 \mathrm{ml}$. of guinea pig serum with $0.4 \mathrm{ml}$. of a $1: 1000$ dilution of "Liquoid" in 0.85 per cent saline for $15 \mathrm{~min}$. at $37^{\circ} \mathrm{C}$. and dilution of the resulting mixture with saline to ten times the original serum volume. ${ }^{3}$ C'2 was tested for indirectly by noting any increased lysis of sensitized sheep red cells over that caused by a fraction of a unit of human $C^{\prime}$ in the presence of heatinactivated guinea pig $C^{\prime}$ to provide adequate amounts of $C^{\prime} 3$ (cf. 7). The results are reported in the table as the highest degree of lysis from 0 to ++++ above that of the reagent controls. In tests for $C^{\prime} 1, C^{\prime} 3$, and $C^{\prime} 4$ the reagent controls showed no lysis but in two series of tests for $C^{\prime} 2$ the human $C^{\prime}$ plus inactivated guinea pig $C^{\prime}$ controls gave ++ and +++ hemolysis, respectively. In the table, therefore, + for $C^{\prime} 2$ represents an increase in lysis to +++ or ++++ , respectively.

The tests for components indicated that all were present in varying amounts in human CSF without any obvious correlation between the strength of the test for a component and total protein content of the CSF. It is difficult to account for the failure of CSF 8,12,16, and 21 to show lysis in the direct test when all four components of $C^{\prime}$ could be shown to be present and when CSF 21, especially, gave such high values at different levels in the indirect test. Possibly, even though $\mathrm{C}^{\prime} 2$, the limiting component of human complement (7), was present in these samples its amount may have been insufficient either to equal a measurable fraction of a $C_{\text {H50 }}^{\prime}$ in $4 \mathrm{ml}$., the largest quantity used in the direct test, or to overcome the anticomplementary properties characteristic of this larger quantity and not present in 1 or $2 \mathrm{ml}$. Moreover, the tests for the components were carried out in a volume of $0.8 \mathrm{ml}$., so that the con-

\footnotetext{
3 Unpublished communication from Professor Graciela Leyton, Santiago, Chile.
}

ditions of these tests were very different from those for total hemolytic activity.

A surprising feature of the component tests was the weakness of many of those for $C^{\prime} 4$, a component usually present in very high titer in the $C^{\prime}$ of human serum (7). No attempt was made to titrate the level of $C^{\prime} 4$.

In some of the cases of this series, such as those with post-traumatic encephalopathies or with brain tumors with CSF in the high total protein range, the presence of $C^{\prime}$ might be accounted for by alterations in the permeability of the meningovascular barrier. There are, nevertheless, other CSF samples showing $C^{\prime}$ activity in which the total protein was within the normal range and the diagnosis indicated no disturbance which would be expected to alter the permeability of the barrier.

The principal outcome of the present studies, therefore, has been to demonstrate the presence of $\mathrm{C}^{\prime}$ or its components in almost all of a series of 22 CSF samples, without obvious relation to the diagnoses of the cases from which the samples were taken or to the protein content of the fluids. Owing to the limitations of the tests themselves and the difficulties of their interpretation it would require study of a very large series of CSF samples before satisfactory answers could be given to questions relating the presence or absence of $\mathrm{C}^{\prime}$ or its components in CSF to the physiology or pathology of the meningo-vascular barrier, or to the diagnosis of any particular disease. It is hoped that the positive findings, on the other hand, will serve to encourage a more detailed and lengthy study.

\section{SUMMARY}

1. About one-third of the samples of CSF taken prior to pneumo-encephalography showed hemolytic $C^{\prime}$ activity when tested directly with sensitized sheep red cells.

2. All but two of 22 samples tested increased lysis by a fractional unit of serum $\mathrm{C}^{\prime}$.

3. Qualitative tests for the four components of $C^{\prime}$ indicated their presence in those samples in which tests were made for all.

4. $C^{\prime}$ activity has been demonstrated in CSF containing protein in normal concentration and in CSF from patients with clinical diagnoses 
compatible with a normal permeability of the meningo-vascular barrier.

\section{BIBLIOGRAPHY}

1. Katzenelbogen, S., The Cerebrospinal Fluid and Its Relation to the Blood. The Johns Hopkins Press, Baltimore, 1935.

2. Fothergill, L. D., Observations on the presence of complement in the cerebrospinal fluid in various pathologic conditions of the central nervous system. J. Pediat., 1935, 6, 374.

3. Okada, T., Experimental studies on the existence of the hemolytic complement in the human cerebrospinal fluid. Sei-I-Kwai M. J., 1929, 48, 5.
4. Mayer, M. M., Eaton, B. B., and Heidelberger, M., Spectrophotometric standardization of complement for fixation tests. J. Immunol., 1946, 53, 31.

5. Mayer, M. M., Osler, A: G., Bier, O. G., and Heidelberger, M., The activating effect of magnesium and other cations on the hemolytic function of complement. J. Exp. Med., 1946, 84, 535.

6. Mayer, M. M., Osler, A. G., Bier, O. G., and Heidelberger, M., Quantitative studies of complement fixation. Proc. Soc. Exp. Biol. \& Med., 1947, 65, 66; J. Immunol., 1948, 59, 195.

7. Bier, O. G., Leyton, G., Mayer, M. M., and Heidelberger, M., A comparison of human and guinea pig complements and their component fractions. J. Exp. Med., 1945, 81, 449.

\section{ASSOCIATION ANNOUNCEMENT}

The 41st annual meeting of the American Society for Clinical Investigation will be held at the Chalfonte-Haddon Hall, Atlantic City, N. J., on Monday, May 2, 1949, at 9 a.m.

For those who may be interested, the annual meeting of the American Association for Research in Psychosomatic Problems will be held at the same hotel on Saturday, April 30, at 9 a.m., and Sunday morning.

The annual meeting of the Association of American Physicians will be held on Tuesday and Wednesday, May 3 and 4, also at the Chalfonte-Haddon Hall. 